\title{
Analisis Karakteristik Traksi Serta Redesign Rasio Transmisi dan Rasio Gardan pada Bus Super Double Decker
}

\author{
Nafi'an Zukhrufal Muttaqi dan I Nyoman Sutantra \\ Departemen Teknik Mesin Fakultas Teknologi Industri, Institut Teknologi Sepuluh Nopember (ITS) \\ e-mail: tantra@me.its.ac.id
}

\begin{abstract}
Abstrak-Pada tahun 2016 penjualan bus di atas 24 ton yang mencapai 106 unit. Serta kurangnya pengetahuan spesifik dari segi transmisi yang memiliki peran penting untuk mengetahui kecepatan dan kemampuan bus untuk melewati tanjakan agar kecelakaan bisa diminimalisir. Sehingga diperlukan beberapa penilitian lebih lanjut untuk mengatasi permasalahan. Dalam penilitan ini, dilakukan tiga tahapan pengujian. Pertama, penulis melakukan perhitungan kecepatan dan percepatan bus. Kedua, melakukan perhitungan tanjakan maksimum dan membuat grafik karakteristik traksi dengan menghitung gaya dorong pada bus. Ketiga, dilakukan evaluasi terhadap karakteristik traksi bus kondisi standar yang kemudian dilanjutkan redesign tingkat transmisi untuk mengoptimalkan kinerja bus dengan menggunakan teori progressi geometri. Dari penelitian ini di dapatkan data berupa kecepatan, percepatan, dan sudut tanjakan pada kondisi standar dari engine yang di analisa serta hasil redesign rasio transmisi bus adiputro dengan engine Mercedes-Benz OC 500 RF 2542. Setelah dilakukan analisa, engine tersebut memiliki kecepatan maksimum yang mampu di tempuh melebihi klaim pabrikan sebesar $128 \mathrm{~km} / \mathrm{jam}$. Sedangkan analisa gradeability yang mampu di capai kendaraan adalah $18 \%$. Setelah dilakukan redesign, gradeability maksimum yang mampu di capai meningkat menjadi $36 \%$.
\end{abstract}

Kata Kunci-Gradeability, Karakteristik Traksi, Progressi Geometri, Redesign.

\section{PENDAHULUAN}

$\mathrm{T}$ EKNOLOGI otomotif semakin berkembang beberapa tahun belakang ini, seiring dengan meningkatnya penjualan kendaraan bermotor di Indonesia. Data pada Gabungan Industri Kendaraan Bermotor Indonesia (Gaikindo) menyebutkan, pada 2016 penjualan bus di atas 24 ton mencapai 106 unit. Pada tahun-tahun sebelum itu, pasar domestik bus banyak diramaikan oleh kategori 5-10 ton dan 10-24 ton. Dalam kategorisasi yang diberlakukan oleh Gaikindo, ada tiga kategori bus yang masuk mobil Indonesia. Selain kategori di atas 24 ton, juga ada kategori 5-10 ton serta kategori 10-24 ton. Penjualan bus dengan kategori 5-10 ton dan kategori 10-24 ton sudah lazim di pasar mobil Indonesia [1]. Hal ini membuktikan kebutuhan akan kendaraan di Indonesia sangat tinggi yang mayoritas digunakan untuk transportasi.

Transportasi di Indonesia beragam mulai dari bus, kereta hingga kapal laut. Bus merupakan kendaraan bermotor yang menjadi transportasi massal yang sangat penting. Mulai dari antar kota hingga antar provisi. Perusahaan Otobus di Indonesia semakin bertambah, hingga sekarang tercatat lebih

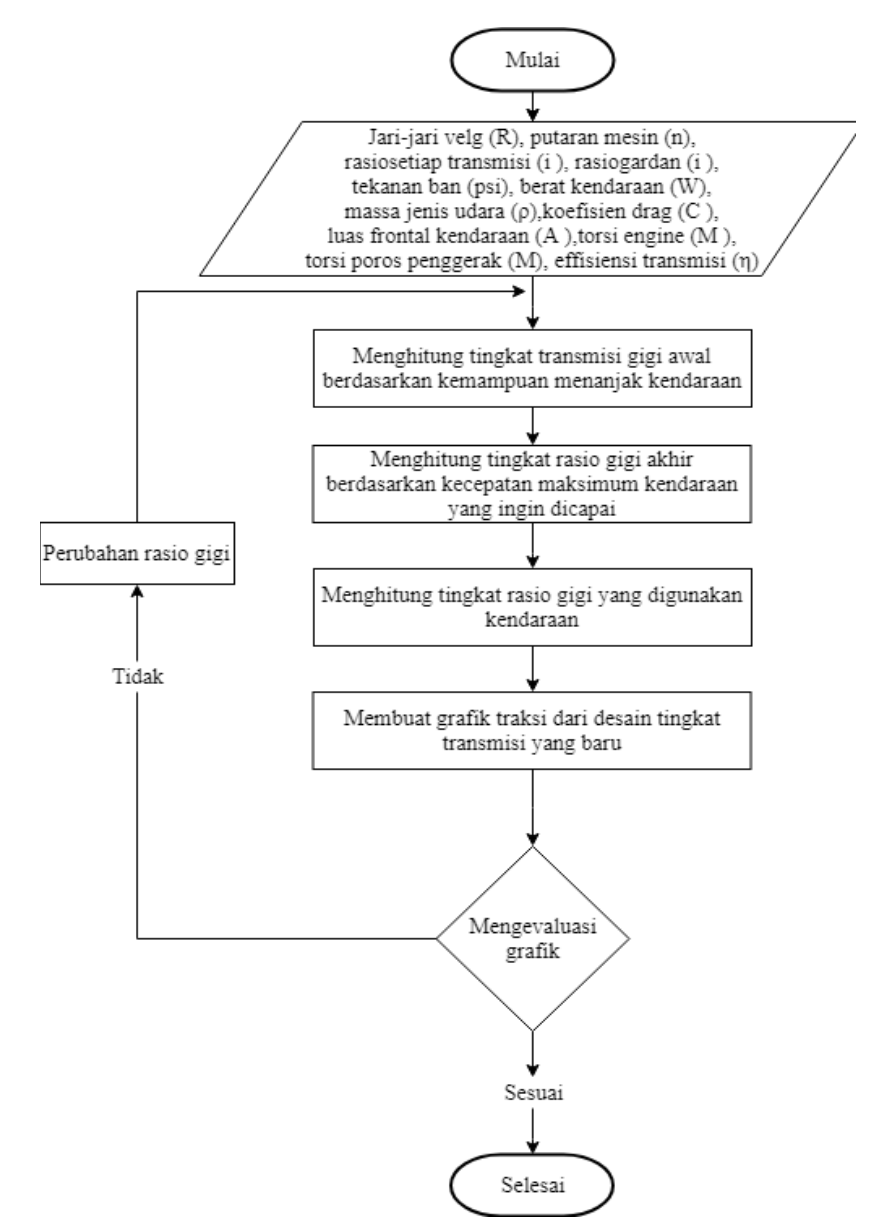

Gambar 1. Flowchart penelitian.

dari 300 perusahaan otobus yang beroperasi. Banyaknya perusahaan otobus membuat armada bus juga semakin banyak. Namun pemilihan untuk menentukan bus yang tepat sesuai dengan kebutuhan kurang dimiliki oleh setiap pemilik perusahaan otobus. Perbedaan kebutuhan spesifikasi bus di karena medan yang di tempuh dan juga kegunaan dari bus itu sendiri.

Bus yang di miliki oleh perusahaan otobus merupakan hasil produksi Perusahaan karoseri. Perusahaan karoseri bus dalam pameran maupun brosurnya hanya menampilkan pengetahuan umum tanpa menyertakan spesifikasi lengkap dari kendaraan. Pengetahuan spesifik dari segi transmisi memiliki peran penting untuk mengetahui kecepatan bus dan kemampuan bus untuk melewati tanjakan, sehingga kecelakaan bisa diminimalisir. Kemampuan kendaraan untuk melaju serta 
mengangkut suatu beban disebut kinerja traksi kendaraan. Pengetahuan kinerja traksi kendaraan yang kurang di ketahui oleh perusahaan otobus dalam pemilihan bus.

Perusahaan karoseri yang ada di Indonesia salah satunya adalah PT. Adiputro Wirasejati. PT. Adiputro Wirasejati memiliki banyak varian bus karoseri yang di produksi termasuk Jetbus 2 SDD. Jetbus 2 SDD menggunakan engine dari pabrikan lain sesuai dengan permintaan. PT. Adiputro Wirasejati sendiri tidak memiliki data performa karakteristik traksi dari engine yang digunakan oleh Jetbus 2 SDD. Beberapa hal diatas yang mendasari penulis untuk melakukan Analisa Karakteristik Traksi serta Redesign Rasio Transmisi dan Rasio Gardan pada Bus Super Double Decker.

\section{METODE PELITIAN}

Adapun metode penelitian yang dilakukan dapat diilustrasikan dalam sebuah flowchart seperti Gambar 1.

\section{A. Studi Literatur}

Penelitian ini diawali dengan melakukan studi literatur. Pada bagian ini dilakukan pengumpulan literatur berupa buku, jurnal serta katalog seputar bus super double decker yang dapat mendukung penelitian tugas akhir ini. Referensi tersebut erat kaitanya dengan penelitian mengenai analisa karakteristik traksi, informasi mengenai spesifikasi kendaraan, serta penelitian mengenai proses redesign rasio transmisi menggunakan metode progresi geometri.

\section{B. Menghitung gaya hambat kendaraan}

Gaya-gaya yang bekerja pada sebuah kendaraan yang sedang melaju pada sebuah permukaan dengan sudut tanjak tertentu dapat dijabarkan dalam Gambar 2.

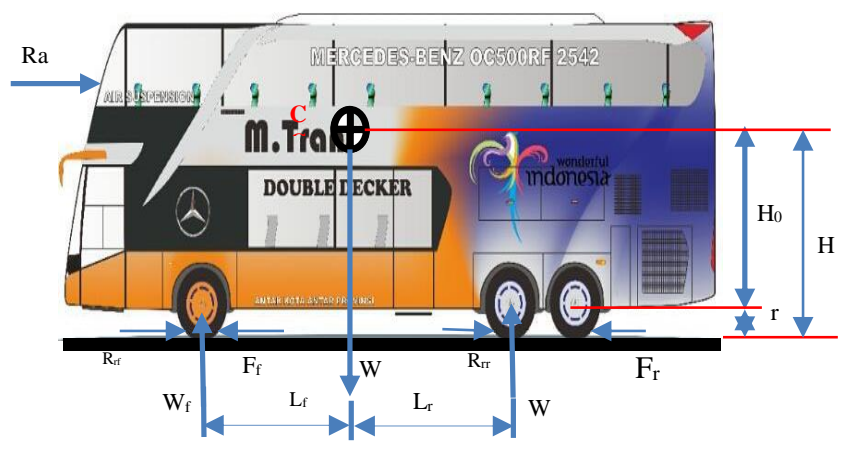

Gambar 2. Dinamika Kendaraan Articulated Bus.

Ft adalah gaya dorong kendaraan oleh mesin pada roda penggerak. Sesuai tujuannya agar dapat memenuhi driver demand, pada gambar 2, Ft (gaya dorong) dibagi menjadi dua yaitu Ff (gaya dorong pada roda depan) dan Fr (gaya dorong pada roda belakang). Gaya dorong pada kendaraan kendaraan yang sedang berjalan, dihambat oleh tiga macam gaya hambat yaitu, drag force, rolling resistance serta gaya hambat kendaraan akibat sudut tanjak [2].

\section{1) Gaya Hambat Aerodinamika}

Gaya hambat karena udara pada mobil disebut dengan drag force. Pada dasarnya, terdapat beberapa jenis gaya hambat angin pada kendaraan yaitu hambatan bentuk, hambatan pusaran, hambatan tonjolan, serta hambatan aliran dalam. Namun, pada dasarnya gaya hambat yang paling besar adalah akibat gaya hambat bentuk dan pusaran. Dengan demikian, besarnya gaya hambat angin dapat dihitung dengan persamaan berikut,

$$
R_{a}=1 / 2 \times \rho \times C_{d} \times A_{f} \times V_{a}{ }^{2}
$$

dimana,

$\mathrm{R}_{\mathrm{a}} \quad=$ hambatan aerodinamika $(\mathrm{N})$

$\rho=$ massa jenis udara $\left(\mathrm{kg} / \mathrm{m}^{3}\right)$

$\mathrm{C}_{\mathrm{d}}=$ koefisien drag

$\mathrm{A}_{\mathrm{f}}=$ Luas frontal kendaraan $\left(\mathrm{m}^{2}\right)$

$\mathrm{V}_{\mathrm{a}}=$ kecepatan relatif angin terhadap kendaraan $(\mathrm{m} / \mathrm{s})$

Besarnya $\mathrm{C}_{\mathrm{d}}$ bus super double decker adalah 0,6 , sedangkan untuk luasan frontal sebesar $10,375 \mathrm{~m}^{2}$.

\section{2) Gaya Hambat Rolling}

Gaya yang kedua adalah rolling resistant. Yaitu gaya hambat akibat gesekan ban dengan jalan. Untuk mencari besarnya gaya hambat rolling, pertama kita harus menentukan besarnya koefisien hambatan rolling (fr) terlebih dahulu. Besarnya Fr dapat dicari menggunakan persamaan hasil eksperimen J.J Taborek berikut [3],

$$
\mathrm{f}_{\mathrm{r}}=\mathrm{f}_{\mathrm{o}}+\mathrm{f}_{\mathrm{s}}\left(\mathrm{V}_{\mathrm{k}} / 100\right)^{2,5}
$$

dimana,

$$
\text { fr } \quad=\text { koefisien hambat rolling }
$$

fo dan $\mathrm{fs}=$ koefisien yang nilainya tergantung pada tekanan ban, didapat dari Gambar 3

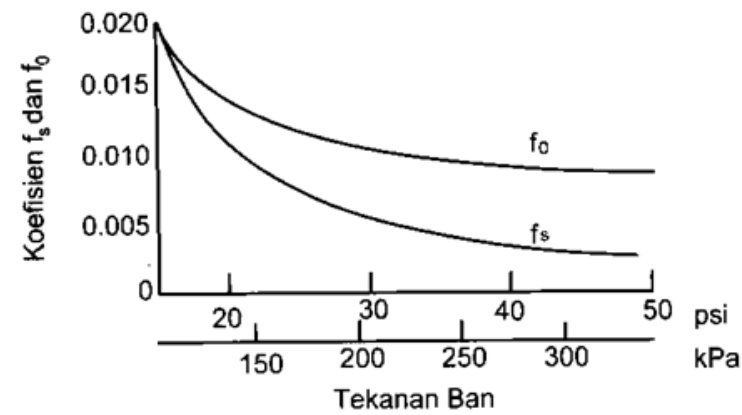

Gambar 3. Tekanan Ban terhadap Koefisien Hambat Rolling [2].

Setelah mendapatkan koefisien hambat rolling $\left(\mathrm{f}_{\mathrm{r}}\right)$, maka besarnya gaya hambat rolling dapat dicari dengan menggunakan persamaan 3 ,

$$
R_{r}=f_{r} x(W)
$$

dimana,

$\mathrm{R}_{\mathrm{r}} \quad$ = gaya hambat resistance pada roda belakang $(\mathrm{N})$

$\mathrm{W}=$ berat Articulated Bus $(\mathrm{N})$

\section{B.3 Gaya Hambat Tanjakan}

Gaya hambat yang ketiga adalah gaya hambat tanjakan, yaitu gaya hambat yang diakibatkan adanya sudut tanjak yang dilewati oleh kendaraan sehingga beban kendaraan akan bertambah akibat gaya gravitasi yang muncul. Besarnya gaya hambat akibat sudut tanjak dapat dihitung dengan persamaan 4 ,

$$
\mathrm{R}_{\mathrm{g}}=\mathrm{W} \sin \theta
$$

Dengan demikian, setelah meninjau tiga buah gaya hambat yang bekerja pada kendaraan sesuai penjelasan sebelumnya, maka gaya hambat total pada kendaraan dapat dirumuskan sesuai persamaan 5 ,

$$
\begin{aligned}
& F_{r}=R_{r}+R_{a}+R_{g} \\
& F_{r}=f_{r} \cdot W \cos \theta_{\max }+\left(1 / 2 \cdot \rho \cdot C_{d} \cdot A_{f} \cdot V_{a}^{2}\right)+W \sin \theta_{\text {masx }}
\end{aligned}
$$




\section{Gaya Dorong Kendaraan}

Gaya Dorong adalah gaya yang bekerja berlawanan dengan arah gerak gaya hambat kendaraan. Gaya dorong ini dihasilkan dari daya yang dihasilkan oleh mesin kendaraan (engine) yang kemudian disalurkan melalui sistem transmisi sehingga akhirnya dapat menggerakan roda. Untuk menghitung besarnya gaya dorong yang mampu dihasilkan kendaraan, dapat digunakan persamaan 6. Selain melalui metode analitis/ perhitungan, untuk mencari besarnya nilai gaya dorong $(\mathrm{Ft})$ aktual pada kendaraan juga dapat dilakukan dengan cara lain. Yaitu dengan melakukan pengujian menggunakan mesin dynotest pada mobil.

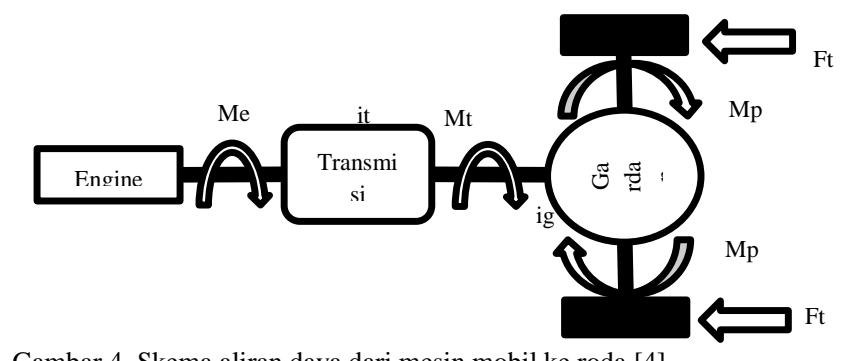

Gambar 4. Skema aliran daya dari mesin mobil ke roda [4].

Gambar 4 adalah gambar skema aliran daya dari mobil yang nantinya dikonversi menjadi gaya dorong. Torsi mesin pada mobil (Me) dihasilkan langsung oleh pembakaran pada combustion engine. Torsi dari engine kemudian akan masuk ke drivetrain. Setelah melalui drivetrain, daya yang disalurkan besarnya akan menurun akibat adanya losses pada drivetrain, kemudian daya akan langsung disalurkan menuju roda kendaraan, torsi yang muncul pada roda disebut Tr. Tr sendiri merupakan kebutuhan torsi untuk menggerakkan kendaraan. Torsi yang muncul pada roda nantinya akan digunakan untuk memutar roda agar bisa bergerak. Pada permukaan roda, ketika berputar akan timbul gaya tangensial. Gaya inilah yang biasa kita sebut dengan gaya dorong $(\mathrm{Ft})$.

Proses transmisi dan transformasi torsi yang dihasilkan oleh mesin menjadi menjadi gaya dorong $(\mathrm{Ft})$ yang terjadi pada roda penggerak dipengaruhi beberapa faktor berikut, Maka, gaya dorong pada roda penggerak $(\mathrm{Ft})$ dengan memperhatikan efisiensi $(\eta \mathrm{t})$ pada semua proses transmisi untuk mobil pada umumnya dirumuskan sebagai berikut,

$$
F t=\frac{i t \cdot i g \cdot M e}{r} \eta t
$$

dimana,

$\mathrm{Ft}$ = gaya dorong pada kendaraan $(\mathrm{N})$

$\mathrm{Me}=$ torsi keluaran dari mesin (N.m)

ne $=$ putaran mesin

ntr $=$ putaran transmisi

$\mathrm{np}=$ putaran poros penggerak

$\mathrm{r} \quad=$ jari-jari roda $(\mathrm{m})$

$\eta \mathrm{t} \quad=$ efisiensi transmisi,

(0.88-0.92) untuk mesin yang letaknya memanjang, poros penggerak belakang

(0.91-0.95) untuk mesin yang letaknya melintang

it $\quad$ perbandingan gigi transmisi

ig = perbandingan transmisi pada garden

Kecepatan maksimum kendaran dalam setiap tingkat transmisi (k) dapat dirumuskan,

$$
V k=\frac{\text { rpm engine }}{i t x i g} x \frac{2 \pi}{60} x(\text { R. roda }) x \frac{3600}{1000}
$$

dimana,

$\mathrm{V}_{\mathrm{k}} \quad=$ kecepatan pada tingkat $\mathrm{k}(\mathrm{km} / \mathrm{h})$

\section{Desain Tingkatan Gigi (Progresi Geometri)}

Transmisi merupakan bagian dari sistem pemindah tenaga dari sebuah kendaraan, yaitu sistem yang berfungsi mengatur tingkat kecepatan dalam proses pemindahan tenaga dari sumber penggerak ke roda kendaraan.

Salah satu cara untuk mencari perbandingan gigi antara tingkat transmisi terendah dan tertinggi adalah dengan cara progresi geometri. Cara ini umumnya dipakai sebagai langkah iterasi awal. Batas kecepatan operasi dari mesin terendah (ne $\left.{ }_{1}\right)$ dan tertinggi $\left(\mathrm{ne}_{2}\right)$ harus ditetapkan terlebih dahulu. Penetapan ini berdasarkan karakteristik torsi dari mesin, batas ini biasa dipilih disekitar torsi maksimum mesin. Konsep dari progresi geometri ditunjukkan pada Gambar 5, dimana menggambarkan transmisi dengan 4 tingkat kecepatan [2].

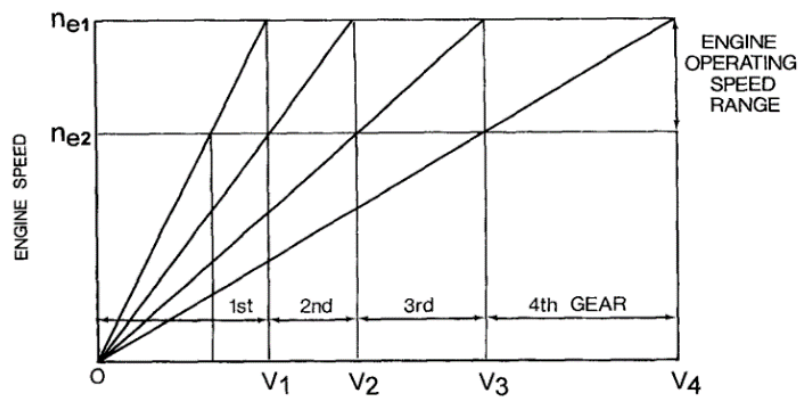

Gambar 5. Grafik pemilihan perbandingan gigi dengan rasio geometri [4].

Berdasarkan gambar 5, dengan perbandingan geometris maka untuk transmisi 4 tingkat didapat hubungan perbandingan gigi seperti persamaan 8 ,

$$
\frac{\mathrm{i} 2}{\mathrm{i} 1}=\frac{\mathrm{i} 3}{\mathrm{i} 2}=\frac{\mathrm{i} 4}{\mathrm{i} 3}=\frac{\mathrm{ne} 2}{\mathrm{ne} 1}=K g
$$

dimana,

$\mathrm{i}_{1}, \mathrm{i}_{2}, \mathrm{i}_{3}, \mathrm{i}_{4}=$ perbandingan gigi pada tingkat transmisi $\mathrm{I}$, II, III, IV

$\mathrm{Kg} \quad=$ konstanta perbandingan

Langkah pertama untuk mendesain tingkat transmisi, harus ditentukan terlebih dahulu rasio transmisi pertama dan rasio transmisi terakhir kendaraan.

Untuk menentukan rasio transmisi pertama, dapat dihitung dengan persamaan 9 ,

$$
i_{1}=\frac{F_{1} \cdot r}{M e \cdot i_{d} \cdot \eta_{t}}
$$

Kemudian, rasio transmisi pada tingkat terakhir (n) dihitung dengan persaam 10 ,

$$
i_{n}=\frac{F_{n} \cdot r}{M e \cdot i_{d} \cdot \eta_{t}}
$$

Dengan demikian, nilai faktor $\mathrm{Kg}$ dapat ditentukan dengan rumus 11. Selanjutnya, nilai $\mathrm{Kg}$ tersebut digunakan untuk menentukan nilai i2, i3 dst.

$$
K g=\left(\frac{i_{n}}{i_{1}}\right)^{\frac{1}{n-1}}
$$


Tabel 1.

Spesifikasi Bus Super Double Decker

\begin{tabular}{|c|c|}
\hline \multicolumn{2}{|l|}{ MESIN DAN TRANSMISI } \\
\hline Mesin & $\begin{array}{l}\text { Mercedes-Benz OM } 457 \text { LA Euro } 3 \\
\text { Diesel, 6-Silinder Segaris, Injeksi Langsung } \\
\text { dengan Turbo charger dan Intercooler }\end{array}$ \\
\hline Diameter/Langkah & $128 / 155 \mathrm{~mm}$ \\
\hline Total Isi Silinder & $11.967 \mathrm{cc}$ \\
\hline Daya Maks & 310 KW (422 hp)@ 1900 rpm \\
\hline Torsi Maks & 1.900 Nm @ 1100 rpm \\
\hline Transmisi & $\begin{array}{l}\text { ZF-Ecolife } 6 \text { AP } 2000 \text { B/3,36 - 0,62 } \\
\text { Transmisi } 6 \text { Kecepatan Maju Dilengkapi } \\
\text { dengan Primary Retarder }\end{array}$ \\
\hline Perbandingan Gigi & $\begin{array}{l}3.36 / 1.910 / 1.420 / 1.000 / 0.720 / 0.620 \mathrm{R}= \\
4.240\end{array}$ \\
\hline Kecepatan Maks & $120 \mathrm{~km} / \mathrm{jam}$ \\
\hline Daya Tanjak & $48 \%$ \\
\hline GANDAR & \\
\hline Depan (1st Axle) & Independent RL75E \\
\hline Kapasitas (1st Axle) & $7.500 \mathrm{~kg}$ \\
\hline Belakang (2nd Axle) & MB - HO $6 / 3$ DCL(S)-13 \\
\hline Perbandingan gigi & $\mathrm{I}=4.3$ \\
\hline Kapasitas (2nd Axle) & $12.000 \mathrm{~kg}$ \\
\hline Belakang (3rd Axle) & ZF RL 75 Actively Steered Trailing Axle \\
\hline Kapasitas (3rd Axle) & $6.000 \mathrm{~kg}$ \\
\hline SUSPENSI & \\
\hline Depan & $\begin{array}{l}\text { Suspensi dengan } 2 \text { Balon Udara } \\
2 \text { Double Acting Shock Absorber, Stabilizer } \\
1 \text { Buah Penyetel Level Kontrol }\end{array}$ \\
\hline Belakang & $\begin{array}{l}\text { Suspensi dengan } 4 \text { Balon Udara } \\
4 \text { Double Acting Shock Absorber, Stabilizer } \\
2 \text { Buah Penyetel Level Kontrol }\end{array}$ \\
\hline PENGEREMAN & \\
\hline Rem Utama & Disc Brake, Full Air Brake System \\
\hline Rem Parkir & $\begin{array}{l}\text { Pegas, Kendali Udara Tekan Penuh Pada } \\
\text { Gandar Belakang }\end{array}$ \\
\hline Rem Tambahan & Exhaust Brake, Constant Throttle, Retarder \\
\hline Tambahan Keselamatan & $\begin{array}{l}\text { EBS (Electronic Braking System) ABS } \\
\text { (Anti-lock Braking System) ASR } \\
\text { (Acceleration Skid System) ESP (Electronic } \\
\text { Stability Program) }\end{array}$ \\
\hline Kemudi & Power Steering ZF - Servocom 8098 \\
\hline Ban \& Pelek & $8.25 \times 22.5 / 295 / 80 \mathrm{R} 22.5$ \\
\hline KELISTRIKAN & \\
\hline Sistem & 24 Volt \\
\hline Altenator & $28 \mathrm{~V} / 140 \mathrm{~A}$ \\
\hline Baterai & $2 \times 12 \mathrm{~V} / 200 \mathrm{Ah}$ \\
\hline Kapasitas Tangki & 415 Liter \\
\hline UKURAN UTAMA & \\
\hline Jarak Sumbu Roda (mm) & 3000 (Pabrik) / 6300 (Maxi) / 6800 (DD) \\
\hline $\begin{array}{l}\text { Jarak Sumbu antar roda } \\
(\mathrm{mm})\end{array}$ & 1350 \\
\hline Julur Depan (mm) & 2570 (Maxi) / 2100 (DD) \\
\hline Julur Belakang (mm) & 2825 \\
\hline Tinggi $(\mathrm{mm})$ & 1700 \\
\hline Panjang Total (mm) & 9275 (Pabrik) / 13500 (Karoseri) \\
\hline Lebar Total (mm) & 2400 \\
\hline $\begin{array}{l}\text { Jarak pijak roda depan } \\
(\mathrm{mm})\end{array}$ & 2088 \\
\hline $\begin{array}{l}\text { Jarak pijak roda Belakang } \\
(\mathrm{mm})\end{array}$ & 2199 \\
\hline Radius Putar (mm) & 11900 \\
\hline Berat Sasis $(\mathrm{kg})$ & 8442 \\
\hline $\begin{array}{l}\text { Berat Kotor Kendaraan } \\
(\mathrm{kg})\end{array}$ & 25500 \\
\hline AERODINAMIKA & \\
\hline $\begin{array}{l}\text { Luas frontal kendaraan } \\
\text { (Af) }\end{array}$ & $10,375 \mathrm{~m} 2$ \\
\hline Massa jenis angin & $1,2 \mathrm{~kg} / \mathrm{m} 3$ \\
\hline Koefisien drag (Cd) & 0,6 \\
\hline
\end{tabular}

Nilai rasio gyrasi ini untuk membuat tingkat rasio transmisi sesuai tujuan penelitian yaitu dapat melebihi kecepatan 80 $\mathrm{km} / \mathrm{jam}$, menanjak hingga 12 derajat dan memiliki losses traksi baik yang dianalisa dari grafik karakteristik traksi untuk setiap tingkat transmisi.

\section{HASIL DAN ANALISIS}

\section{A. Informasi Umum}

Beberapa informasi mengenai spesifikasi Jetbus 2 Super Double Decker Adiputro disajikan pada Tabel 1.

Informasi umum standar bus super double decker tersebut memiliki beberapa batasan:

1. Kendaraan yang dianalisa adalah Jetbus 2 Super Double Decker Adiputro.

2. Mesin yang digunakan adalah Mercedes-Benz OC 500 RF-2542.

3. Tekanan ban 60 psi.

4. Jalan yang dilalui rata (tidak bergelombang).

5. Kinerja engine tidak dipengaruhi lingkungan sekitar.

6. Beban angin yang terjadi pada kendaraan yaitu gaya hambat (drag).

7. Analisa yang dilakukan dalam kondisi bus terisi penuh dengan berat masing masing orang $75 \mathrm{~kg}$.

Beban angin yang terjadi pada kendaraan yaitu gaya hambat aerodinamis, gaya hambat rolling dan gaya hambat tanjak menjadi gaya hambat total yang dilawan oleh gaya dorong $(\mathrm{Ft})$ jika diolah akan memiliki karakteristik traksi seperti pada Gambar 6.

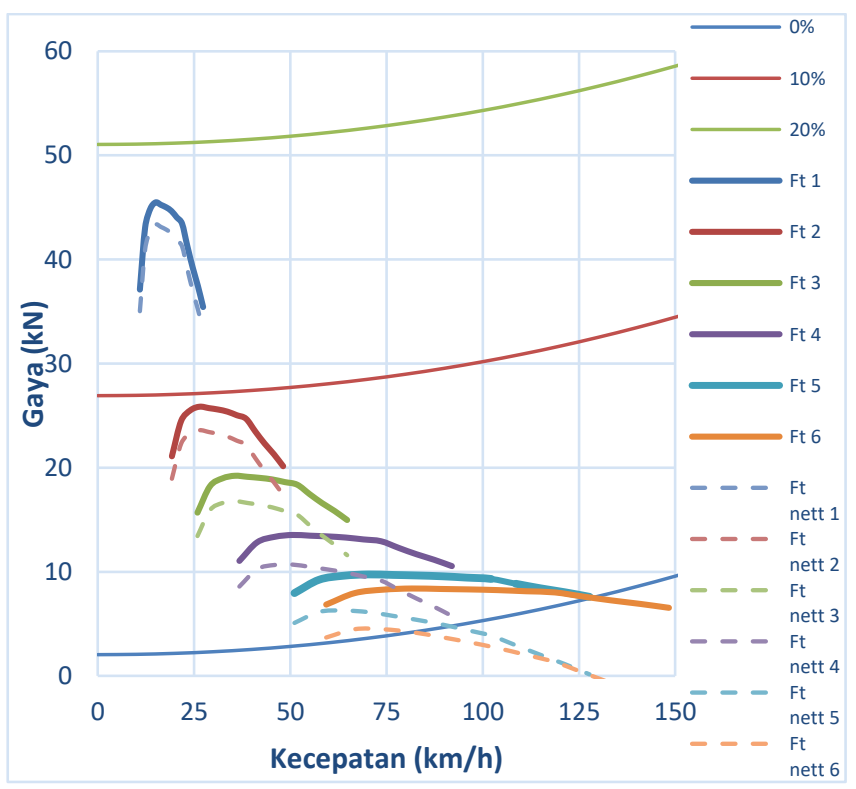

Gambar 6. Grafik Karakteristik Traksi Pada Keadaan Standar.

Kemudian menentukan tingkat gigi Dalam mendesain tingkat gigi pertama diestimasikan percepatan (a) yang mampu dicapai sebesar $3,28 \mathrm{~m} / \mathrm{s} 2$. Nilai berat kendaraan (W) 250.155 N. Gaya hambat rolling dan udara pada tingkat satu ditentukan memiliki kecepatan maksimum $13 \mathrm{~km} / \mathrm{jam}$, Nilai $\mathrm{Rr}$ sebesar 2.042,3 N dan Ra sebesar 48,8 N. Dengan demikian, besarnya gaya hambat total yang dialami mobil pada tingkat gigi pertama dengan persamaan 5 adalah,

$$
F_{1}=\frac{250155}{9.81} 3.28642+2042.331+48.705
$$




$$
F_{1}=85894.9 \mathrm{~N}
$$

Selanjutnya dalam mendesain tingkat gigi pertama adalah mengunakan persamaan 9 ,

$$
\begin{gathered}
i_{1}=\frac{85894.9 \times 0.525}{1900 \times 4.3 \times 0.87} \\
i_{1}=6.34432
\end{gathered}
$$

Rasio tingkat gigi terakhir ditentukan berdasarkan kecepatan maksimum yang diharapkan mampu dicapai oleh kendaraan, yaitu $140 \mathrm{~km} / \mathrm{jam}$. Saat berada pada tingkat gigi terakhir, beban yang dialami kendaraan terdiri dari gaya hambat angin serta gaya hambat rolling, sehingga besarnya gaya total adalah,

$$
\begin{gathered}
F n=5648,611+2927,057 \\
F n=8575.668
\end{gathered}
$$

Selanjutnya, dengan menggunakan persamaan 10 , didapatkan rasio tingkat gigi terakhir,

$$
\begin{gathered}
i_{n}=\frac{8575.668 \times 0.525}{1900 \times 4.3 \times 0.87} \\
i_{n}=0.63341
\end{gathered}
$$

Dengan perhitungan nilai rasio tingkat gigi terakhir dan gigi awal kita akan mendapatkan nilai rasio gyrasi untuk menetapkan tingkatan rasio gigi redesign, seperti tabel 2,

Tabel 2

Perbandingan Tingkatan Gigi Transmisi Redesign

\begin{tabular}{ccccc}
\hline \hline Tingkat & Standar & 6 & 7 & 8 \\
\hline Kg & 0.7132 & 0.63075 & 0.68111 & 0.71952 \\
Rasio 1 & 3.36 & 6.34432 & 6.34432 & 6.34432 \\
Rasio 2 & 1.91 & 4.00171 & 4.32118 & 4.56487 \\
Rasio 3 & 1.42 & 2.52409 & 2.94319 & 3.28451 \\
Rasio 4 & 1.00 & 1.59208 & 2.00464 & 2.36327 \\
Rasio 5 & 0.72 & 1.00421 & 1.36438 & 1.70042 \\
Rasio 6 & 0.62 & 0.63341 & 0.92997 & 1.22349 \\
Rasio 7 & & & 0.63341 & 0.88032 \\
Rasio 8 & & & & 0.63341 \\
\hline \hline
\end{tabular}

\section{B. Hasil Traksi Redesign Transmisi}

Setelah melakukan Progressi Geometri didapat beberapa grafik untuk menilai kecepatan maksimal yang mampu dicapai, kemampuan tanjak (gradeibility) dan losses yang terjadi. Grafik tersebut terpapar pada Gambar 7 sampai Gambar 12.

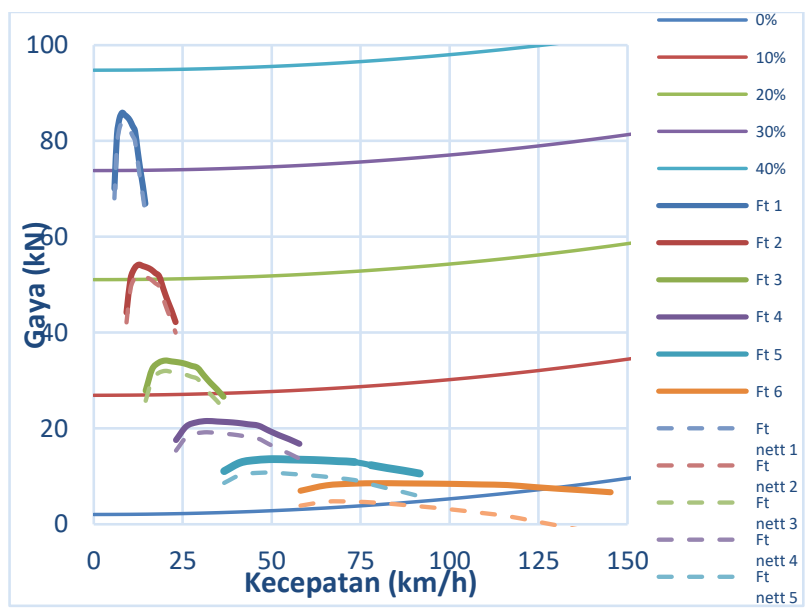

Gambar 7. Grafik karakteristik traksi 6 tingkat hasil redesign.

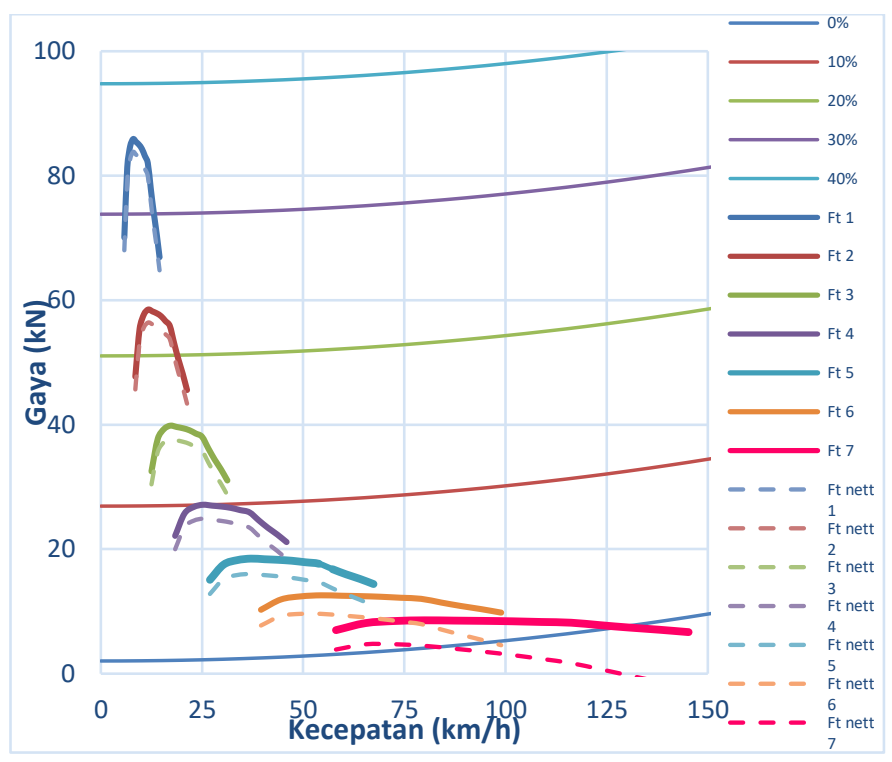

Gambar 8. Grafik karakteristik traksi 7 tingkat hasil redesign

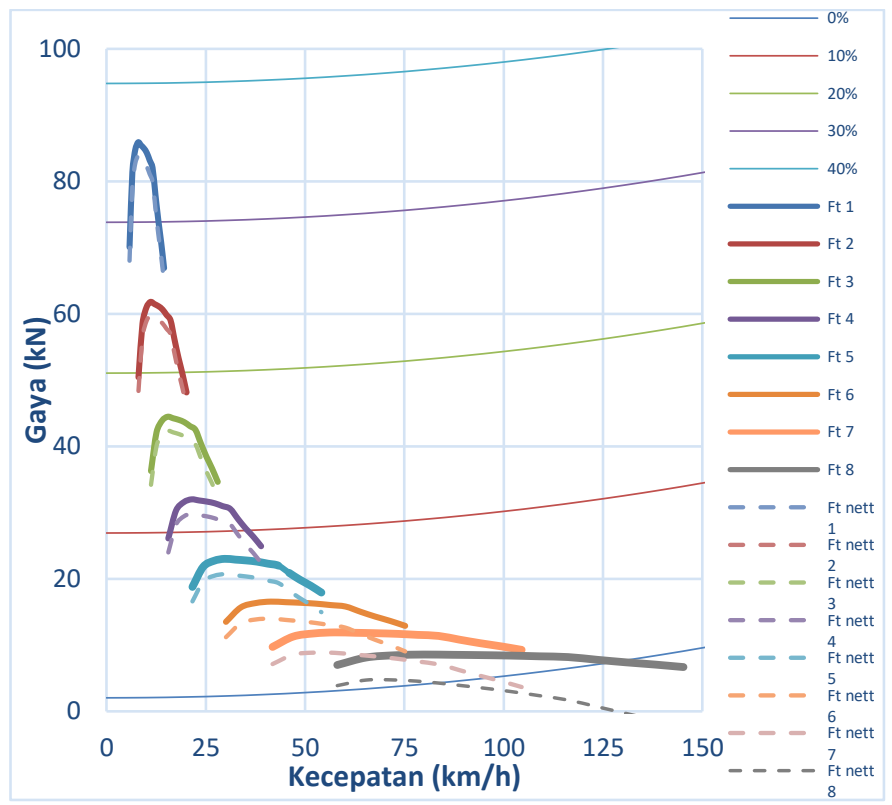

Gambar 9. Grafik karakteristik traksi 8 tingkat hasil redesign.

Dari Gambar 8 hingga 10 didapatkan tingkat transmisi hasil redesign mampu menanjak dengan greadeability sekitar $36 \%$. Kecepatan maksimal yang bisa dicapai hingga 128 km/jam. Pada redesign 6 tingkat kecepatan, besarnya losses energy antara transmisi pertama dan kedua sekitar sebesar 13,2 kN. Kemudian pada redesign 7 tingkat kecepatan, besarnya losses energy antara transmisi pertama dan kedua sekitar sebesar $9,02 \mathrm{kN}$. Sedangkan pada redesign 8 tingkat kecepatan, besarnya losses energy antara transmisi pertama dan kedua sekitar sebesar $6,25 \mathrm{kN}$.

\section{Pemilihan Jumlah Transmisi}

Perbandingan kali ini membandingkan beberapa faktor yang ada pada transimi. Faktor-faktor tersebut antara lain, dimensi konstruksi transmisi, distribusi traksi (losses energy) yang terjadi, kecepatan dan gradeability yang dihasilkan pada setiap tingkat giginya. Perbandingan tersebut dijelaskan pada Tabel 3. 
Tabel 3

Perbandingan Faktor pada Transmisi

\begin{tabular}{ccccc}
\multicolumn{5}{c}{ Perbandingan Faktor pada Transmisi } \\
\hline \hline Faktor & Standart & $\begin{array}{c}\text { Redesign 6 } \\
\text { (GO 230-6 } \\
\text { E) }\end{array}$ & $\begin{array}{c}\text { Redesign } \\
7\end{array}$ & $\begin{array}{c}\text { Redesign 8 (GO } \\
\text { 240-8 EPS3K) }\end{array}$ \\
\hline $\begin{array}{c}\text { Dimensi Konstruksi } \\
\text { Transmisi }\end{array}$ & $732 \mathrm{~mm}$ & $788 \mathrm{~mm}$ & - & $788 \mathrm{~mm}$ \\
Distribusi Traksi & $9.83 \mathrm{kN}$ & $18.7 \mathrm{kN}$ & $9.3 \mathrm{kN}$ & $13.5 \mathrm{kN}$ \\
Kecepatan & 128 & $127 \mathrm{~km} / \mathrm{j}$ & $128 \mathrm{~km} / \mathrm{j}$ & $128 \mathrm{~km} / \mathrm{j}$ \\
& $\mathrm{km} / \mathrm{j}$ & & & \\
Gradeability & $18 \%$ & $38 \%$ & $36 \%$ & $39 \%$ \\
\hline \hline
\end{tabular}

Tabel 4

Pemilihan Jumlah Tingkat Transmisi Berdasarkan Bobot Faktor Tertentu

\begin{tabular}{ccccc}
\hline \hline Faktor & Bobot & $\begin{array}{c}\text { Redesign 6 (GO } \\
230-6 \mathrm{E})\end{array}$ & $\begin{array}{c}\text { Redesign } \\
7\end{array}$ & $\begin{array}{c}\text { Redesign 8 (GO 240- } \\
8 \text { EPS3K) }\end{array}$ \\
\hline Dimensi & 0.35 & 3 & 2 & 3 \\
Transmisi & & & 3 & 2 \\
Distribusi & 0.15 & 1 & & \\
Traksi & & & 2 & 2 \\
Kecepatan & 0.25 & 2 & 2 & 2 \\
Gradeability & 0.25 & 2 & 2.15 & 2.35 \\
Jumlah & 1 & 2.2 &
\end{tabular}

Keterangan: $1=$ Buruk $2=$ Cukup $3=$ Baik

Menggunakan metode pemeringkatan faktor, maka dapat ditentukan jumlah tingkat transmisi yang paling tepat berdasarkan penilaian bobot tertentu pada setiap faktornya. Faktor - faktor tersebut antara lain, dimensi transmisi, distribusi traksi yang terjadi dan kecepatan serta greadibility yang dihasilkan pada setiap tingkat giginya. Dimensi transmisi diestimasikan dengan mendata transmisi di pasaran. Detail untuk tiap tingkatnya adalah GO 230-6 E (6 tingkat) dengan panjang $788 \mathrm{~mm}$, GO 240-8 EPS3K (8 tingkat) dengan panjang $788 \mathrm{~mm}$. Sedangkan untuk transmisi dengan 7 tingkat percepatan, tidak ada data untuk pabrik yang sudah membuat transmisi 7 tingkat percepatan, maka dari itu harus membuat transmisi sendiri. Ukuran panjang tingkatan transmisi yang paling mendekati ukuran 6 tingkat (standar) memiliki nilai bobot lebih baik. Diameter transmisi tidak menjadi pertimbangan dikarenakan diameter transmisi lain lebih kecil daripada transmisi standardnya, untuk GO 230-6 E (6 tingkat) dan GO 240-8 EPS3K (8 tingkat) hanya $530 \mathrm{~mm}$ sementara transmisi standar memiliki diameter $553 \mathrm{~mm}$.

Distribusi traksi yang memiliki nilai lebih baik adalah tingkatan redesign dengan losses paling baik. Pembobotan distribusi traksi didapatkan berdasarkan perhitungan besarnya losses traksi pada tingkat gigi pertama menuju tingkat gigi kedua. Kondisi standar memiliki nilai losses traksi sebesar $9.83 \mathrm{kN}$, kemudian hasil GO 230-6 E (6 tingkat) nilai losses traksi sebesar $18.7 \mathrm{kN}$, kemudian hasil redesign 7 tingkat nilai losses traksi sebesar $9.3 \mathrm{kN}$, kemudian hasil GO 240-8 EPS3K (8 tingkat) nilai losses traksi sebesar $13.5 \mathrm{kN}$. Artinya losses traksi dapat diminimalisir dengan menambah jumlah tingkatan kecepatan. Nilai losses paling kecil memiliki nilai bobot paling besar. Untuk nilai greadibility dan kecepatan sama bobotnya, dikarenakan memiliki nilai yang sama seperti ditunjukan pada perhitungan yaitu mampu menanjak dalam greadibility sekitar $38 \%$ dan kecepatan maksimal $127 \mathrm{~km} / \mathrm{jam}$

Berdasarkan tabel 4, dengan mempertimbangkan faktorfaktor yang telah disebutkan sebelumnya, dapat disimpulkan bahwa transmisi hasil redesign dengan engine Mercedes-Benz OC 500 RF-2542 membutuhkan transmisi GO 240-8 EPS3K (8 tingkat) dikarenakan memiliki poin paling besar.

\section{KESIMPULAN/RINGKASAN}

Kesimpulan berdasarkan data dan analisa yang telah dilakukan, diperoleh beberapa kesimpulan penelitian sebagai berikut. Pada kondisi standar, kendaraan bus super double decker dengan engine Mercedes-Benz Premium Chassis OC 500 RF 2542 mampu menempuh kecepatan maksimum sebesar $128 \mathrm{~km} / \mathrm{jam}$ pada tingkat gigi ke-enam dan mampu melaju pada jalan dengan gradeability maksimum $18 \%$ dan percepatan maksimum pada jalan datar sebesar $1.70125 \mathrm{~m} / \mathrm{s}^{2}$ pada tingkat kecepatan pertama.

Setelah dilakukan redesign pada 6,7, maupun 8 tingkat kecepatan, traksi yang dihasilkan oleh kendaraan meningkat dari $45.49056 \mathrm{kN}$ menjadi $85.8948 \mathrm{kN}$ pada tingkat gigi pertama pada putaran $1100 \mathrm{rpm}$. Peningkatan gaya dorong tersebut mengakibatkan kemampuan kendaraan untuk melalui jalan tanjak dengan gradeability sebesar 36\% dari kondisi standart $18 \%$. Kecepatan maksimum yang dapat di capai sama seperti keadaan standar yaitu sebesar $128 \mathrm{~km} / \mathrm{jam}$.

Pemilihan transmisi yang tepat untuk bus super double decker dari hasil analisa traksi dan redesign ratio transmisi adalah dengan menggunakan transmisi GO 240-8 EPS3K dengan rasio tiap transmisinya $6.571 ; 4.158 ; 2.748 ; 1.739$; $1.259 ; 1.000 ; 0.797 ; 0.633$, karena memiliki gaya dorong yang mampu menanjak dengan gradeability $39 \%{ }^{[8]}$. Kecepatan maksimum yang dapat di capai yaitu sebesar $128 \mathrm{~km} / \mathrm{jam}$, sama dengan kecepatan maksimum pada kondisi standar meskipun masih terdapat losses energy yang terjadi. Akan tetapi dengan menggunakan transimisi yang sudah ada yaitu transmisi GO 240-8 EPS3K maka tidak perlu untuk merancang dan membuat tranmisi baru sehingga lebih efektif.

Saran penulis yang pertama adalah perlu dilakukan analisa lebih lanjut mengenai desain detail susunan transmisi sebelum dan setelah dilakukan redesign agar dapat dipertimbangkan untuk produksi massal. Kemudian perlu dilakukan analisa perhitungan menggunakan efisiensi aktual yang dapat ditentukan menggunakan pengujian dyno test pada kendaraan agar karakteristik traksi hasil perhitungan mendekati karakteristik traksi kendaraan pada kondisi aktual dan yang terakhir setelah dilakukannya analisis diatas maka disarankan untuk menggunakan transmisi GO 240-8 EPS3K sebagai pengganti transmisi yang dipakai agar didapatkan kemampuan tanjak yang lebih baik dan losses energy yang lebih sedikit.

\section{DAFTAR PUSTAKA}

[1] Gaikindo, "Pasar Domestik Fluktuatif, Penjualan Doubel Cabin Melesat," $2017 . \quad$ [Online]. Available: https://www.gaikindo.or.id/data-gaikindo-pasar-domestik-fluktuatifpenjualan-double-cabin-melesat/.

[2] B. S.I. Nyoman., Sampurno, Teknologi Otomotif Edisi Kedua. Guna Widya, 2010.

[3] J. J. Taborek, Mechanics of Vehicles. Ohio: Penton Publishing Co, 1957. 